\title{
Evolving the Physical Global Ocean Observing System for Research and Application Services Through International Coordination
}

\section{OPEN ACCESS}

Edited by:

Marlon R. Lewis,

Dalhousie University, Canada

Reviewed by:

Stan Wilson,

Independent Researcher, Baltimore,

United States

A. J. Dolman,

Vrije Universiteit Amsterdam

Netherlands

Magdalena Alonso Balmaseda,

European Centre for Medium-Range Weather Forecasts, United Kingdom

Yuhei Takaya,

Meteorological Research Institute (MRI), Japan

*Correspondence:

Bernadette M. Sloyan

Bernadette.Sloyan@csiro.au

Specialty section:

This article was submitted to

Ocean Observation,

a section of the journal

Frontiers in Marine Science

Received: 12 December 2018

Accepted: 05 July 2019

Published: 06 August 2019

Citation:

Sloyan BM, Wilkin J, Hill KL,

Chidichimo MP, Cronin MF,

Johannessen JA, Karstensen J, Krug M, Lee T, Oka E, Palmer MD,

Rabe B, Speich S, von Schuckmann K, Weller RA and Yu W (2019) Evolving the Physical

Global Ocean Observing System for Research and Application Services

Through International Coordination.

Front. Mar. Sci. 6:449.

doi: 10.3389/fmars.2019.00449
Bernadette M. Sloyan ${ }^{*}$, John Wilkin², Katherine Louise Hill', Maria Paz Chidichimo4, Meghan F. Cronin ${ }^{5}$, Johnny A. Johannessen ${ }^{6}$, Johannes Karstensen ${ }^{7}$, Marjolaine Krug 8 , Tong Lee ${ }^{9}$, Eitarou Oka ${ }^{10}$, Matthew D. Palmer ${ }^{11}$, Benjamin Rabe ${ }^{12}$, Sabrina Speich ${ }^{13}$, Karina von Schuckmann ${ }^{14}$, Robert A. Weller ${ }^{15}$ and Weidong Yu ${ }^{16}$

${ }^{1}$ CSIRO Oceans and Atmosphere and Centre for Southern Hemisphere Oceans Research, Hobart, TAS, Australia, ${ }^{2}$ Rutgers, The State University of New Jersey, New Brunswick, NJ, United States, ${ }^{3}$ Global Ocean Observing System, Global Climate Observing System, World Meteorological Organization, Geneva, Switzerland, ${ }^{4}$ Consejo Nacional de Investigaciones Científicas y Técnicas (CONICET), Servicio de Hidrografía Naval and Instituto Franco-Argentino sobre Estudios de Clima y sus Impactos (UMI-IFAECI-CNRS), Buenos Aires, Argentina, ${ }^{5}$ National Oceanic and Atmospheric Administration (NOAA) Pacific Marine Environmental Laboratory, Seattle, WA, United States, ${ }^{6}$ Nansen Environmental and Remote Sensing Center and University of Bergen, Bergen, Norway, ${ }^{7}$ GEOMAR Helmholtz Centre for Ocean Research Kiel, Kiel, Germany, ${ }^{8}$ Council for Scientific and Industrial Research (CSIR), Cape Town, South Africa, ${ }^{9}$ National Aeronautics and Space Administration (NASA) Jet Propulsion Laboratory, Pasadena, CA, United States, ${ }^{10}$ Atmosphere and Ocean Research Institute, The University of Tokyo, Chiba, Japan, ${ }^{11}$ Met Office Hadley Centre, Exeter, United Kingdom, ${ }^{12}$ Alfred-Wegener-Institut Helmholtz-Zentrum für Polar- und Meeresforschung, Bremerhaven, Germany, ${ }^{13}$ École Normale Supérieure, Laboratoire de Météorologie Dynamique, Institut Pierre-Simon Laplace, Paris, France, ${ }^{14}$ Mercator Ocean International,

Ramonville-Saint-Agne, France, ${ }^{15}$ Woods Hole Oceanographic Institution, Woods Hole, MA, United States, ${ }^{16}$ National Marine Environmental Forecasting Center, Beijing, China

Climate change and variability are major societal challenges, and the ocean is an integral part of this complex and variable system. Key to the understanding of the ocean's role in the Earth's climate system is the study of ocean and sea-ice physical processes, including its interactions with the atmosphere, cryosphere, land, and biosphere. These processes include those linked to ocean circulation; the storage and redistribution of heat, carbon, salt and other water properties; and air-sea exchanges of heat, momentum, freshwater, carbon, and other gasses. Measurements of ocean physics variables are fundamental to reliable earth prediction systems for a range of applications and users. In addition, knowledge of the physical environment is fundamental to growing understanding of the ocean's biogeochemistry and biological/ecosystem variability and function. Through the progress from OceanObs'99 to OceanObs'09, the ocean observing system has evolved from a platform centric perspective to an integrated observing system. The challenge now is for the observing system to evolve to respond to an increasingly diverse end user group. The Ocean Observations Physics and Climate panel (OOPC), formed in 1995, has undertaken many activities that led to observing system-related agreements. Here, OOPC will explore the opportunities and challenges for the development of a fit-for-purpose, sustained and prioritized ocean observing system, focusing on physical variables that maximize support for fundamental research, climate monitoring, forecasting on different timescales, and society. OOPC recommendations are guided by the Framework for Ocean Observing which emphasizes identifying user requirements by considering time and space scales 
of the Essential Ocean Variables. This approach provides a framework for reviewing the adequacy of the observing system, looking for synergies in delivering an integrated observing system for a range of applications and focusing innovation in areas where existing technologies do not meet these requirements.

Keywords: observing system evaluation, observing system design, sustained observations, observing networks, observation platforms, climate, weather, operational services

\section{SOCIETAL REQUIREMENTS FOR OCEAN OBSERVATIONS}

That the ocean plays a central role in the Earth system is well known. Planetary scale transport of heat, freshwater and carbon by the ocean rivals that of the atmosphere, and the ocean's storage capacity for these quantities leads to slow modes of propagation that extend the predictability of climate conditions and have enabled the development of practical climate forecasting systems on seasonal to decadal time scales (e.g., Smith et al., 2012; DoblasReyes et al., 2013; Kirtman et al., 2013; Meehl et al., 2014). Much of the information that underpins these prediction systems comes from globally coordinated ocean basin scale observing systems.

For example, impacts of a predicted weakening of the Atlantic Meridional Overturning Circulation (AMOC) (e.g., Caesar et al., 2018) may already be evident in changing patterns of summer atmospheric circulation and heat waves in Europe (Duchez et al., 2016; Frajka-Williams et al., 2017) and in accelerating rates of sea level rise on the U.S. East Coast (e.g., Yin et al., 2009; Caesar et al., 2018). In the South Atlantic Ocean, numerical models have shown that low-frequency AMOC variations may influence decadal variability of global atmospheric circulation patterns (e.g., Lopez et al., 2016). The tropical Pacific's El Niño-Southern Oscillation (ENSO) dramatically affects global climate including regional temperature, precipitation, severe weather, marine and terrestrial ecosystems, fisheries and human activities (Timmermann et al., 2018; Smith et al., 2019). In Australia the severe droughts of 1982, 1994, 2002, and 2006

Abbreviations: AOPC, Atmopsheric Observations Panel for Climate; AMOC, Atlantic Meridional Overturning Circulation; CLIVAR, Climate and Ocean: Variability, Predictability and Change; CCCO, Committee on Climate Chagne and the Ocean; COES, Committee on Earth Observations Satellites; DOOS, Deep Ocean Observing Strategy; ENSO, El Niño-Southern Oscillation; ECVs, Essential Climate Variables; EOVs, Essential Ocean Variables; XBT, eXpendable Bathy Thermograph; FOO, Framework for Ocean Observing; GCOS, Global Climate Observing System; GODAE, Global Ocean Data Assimilation Experiment; GOOS, Global Ocean Observing System; GO-SHIP, Global Ocean Ship-based Hydrographic Program; GHRSST, Group for High Resolution Sea Surface Temperature; IOGOOS, Indian Ocean Global Ocean Observing System; IndOOS, Indian Ocean Observing System; IMBeR, Integrated Marine Biosphere Research; IOC, Intergovernmental Oceanographic Commission; ICSU, International Council for Science; IOCCP, International Ocean Carbon Coordination Project; IPCC, International Panel on Climate Change; IQuOD, International Quality Controlled Ocean Dsatabase; JCOMM, Joint WMO-IOC Technical Commission on Oceanography and Marine Meteorology; OCG, Ocean Coordination Group; OOPC, Ocean Observations Physics and Climate panel; OOSDP, Ocean Observing System Development Panel; SCOR, Scientific Committee on Oceanic Research; SOOP, Ship-of-Opportunity Programme; TOPC, Terrestrial Observation Panel for Climate; TOGA, Tropical Oceans Global Atmosphere; TAOS, Tropical Atlantic Observing System; TPOS, Tropical Pacific Observing System; WOCE, World Climate Circulation Experiment; WMO, World Meteorological Organization; WCRP, World Ocean Research Programme. were all associated with ENSO, while in South America reduced precipitation is observed in north/north-eastern South America and enhanced precipitation is found in south-eastern South America during ENSO events, with the opposite during La Niña events (Tedeschi et al., 2016).

At the coasts, rising sea level is increasing the probability that storm surge, or even the regular cycle of the tides, will produce sea level extremes that damage property and infrastructure, and present an immediate risk to human safety. This may be exacerbated by damage wrought by more frequent tropical storms of increasing duration and severity (Webster et al., 2005; Vecchi and Soden, 2007; IPCC, 2014). Coastal areas are densely populated, with about $27 \%$ of the global population living along the coastal fringes as of 2010 (Kummu et al., 2016). Many of these communities depend on the ocean for subsistence, livelihood, and general well-being through food provision, tourism, recreation, transportation services, water supply, and energy. In addition, for communities living by the sea, the ocean is also frequently a key aspect of their cultural identity (e.g., Marzeion and Levermann, 2014).

Ocean temperature extremes, commonly referred to as marine heatwaves (Hobday et al., 2018), impact marine habitats and ecosystems through thermal stress. There is a risk of increased frequency of marine heatwaves, which imperil coral reefs due to increased bleaching events. The marine heatwaves off Australia in 2016 has been linked to coral bleaching in the Great Barrier Reef (Hughes et al., 2018). In addition to natural variability and human-induced climate trends, ocean ecosystems are also vulnerable to direct anthropogenic forcing from overfishing, pollutant contamination, pathogens, coastal development, and maritime operations related to resource use and tourism.

In climate prediction (seasonal to decadal) and projection (centennial), demonstrating the veracity of coupled climate models with respect to future climate conditions relies on the ability to show meaningful skill in reproducing past climate variability by comparison to long observational time series. Seasonal and decadal prediction systems will rely principally on accurately forecasting the slow ocean modes and their role in modulating the fast atmosphere (Kirtman et al., 2013). In order to predict climate, models (coupled or ocean only) must be initialized with the ocean observations. Timely and sustained ocean observations, both satellite and in situ, will be crucial for the development of skillful climate predictions that meet societal expectations and needs (Smith et al., 2012).

The decades of oceanographic observation by research vessels, ships of opportunity, research and operational satellites, and experimental platforms and sensors, have contributed immeasurably to our knowledge of the ocean and our ability 
to respond usefully to calls for information regarding the important societal needs noted above. The ocean observing system remained relatively sparse and regionally-focused until the 1990s (Gould et al., 2013). These human pressures also need to be observed and monitored if their influence is to be placed in proper context compared to change driven by climate variability and change. In the decade since OceanObs'09, the use of autonomous in situ platforms has revolutionized the ocean observing system. Yet despite these successes, it remains that many of these data sets are brief relative to the time scales of natural variability (e.g., Jones et al., 2016) and trends or long-term cycles. Nevertheless, the data that the present observing system has delivered have been crucial in developing our understanding of the oceanic state, change and their underlying processes and their relation to observed climate variability to the extent that we can offer actionable guidance to users and stewards of the ocean environment. Sustained full-depth monitoring of ocean physical and biogeochemical parameters is required to deliver this information in order to determine our human influence upon the observed changes in the ocean.

It is anticipated that further technological advances in platforms and physical and biogeochemical sensors will continue to improve our ability to observe the ocean. Ensuring that the suite of ocean observations is adequate for the many uses to which they are put, and truly global in scope, demands a coordinated approach to using vessels, the deployment of instruments in the ocean, and satellite remote sensing in a manner that is complementary to their respective capabilities and meets agreed requirements for data quality, sampling frequency and geographic coverage. There are still many gaps and the observing system requires expansion into many regions that are poorly sampled or have simply never been visited (e.g., some shelf areas, marginal seas, sea ice covered oceans and the deep ocean below $2000 \mathrm{~m}$ ) to further improve assessments of the status of the global climate (e.g., von Schuckmann et al., 2016; Johnson et al., 2018).

Even for fundamental physical observations such as temperature and sea level, these requirements are difficult to quantify because of the diversity of potential users and observing technologies, and inevitable practical limitations on resources. As new observing technologies arise and analysis methods advance, the requirements for sustained observing should adapt and evolve if the system is to remain efficient and effective. Given the preponderance of pressing societal needs related to food supply, water quality and environmental health, coupled with emerging capabilities for observing the ocean's chemistry and key biological variables for ecosystems, it is becoming increasingly important to move beyond ocean physical variables to develop coordinated multidisciplinary observing technologies and systems to monitor and assess the status of marine ecosystems under different stressors. To date, this is only possible for a restricted number of variables and limited to regional scales (Miloslavich et al., 2018).

Given the increasing complex mix of observing platforms and sensor technologies, and the ever expanding users and their differing and sometimes divergent requirements, the Ocean Observations Physics and Climate panel (OOPC) faces new challenges. These challenges included the expanded role of OOPC to provide science-based recommendations for a fitfor-purpose, sustained and prioritized ocean observing system, that maximizes support for fundamental research, climate monitoring, forecasting on different timescales, and society. In this paper we take stock of progress to date; OOPC achievements and anticipated future challenges and opportunities to develop an integrated and consistent ocean observing for the future.

\section{OCEAN OBSERVATION COORDINATION EFFORTS}

The history of OOPC is linked to major milestones in the development of the sustained ocean observing system. The predecessor to the OOPC was the Ocean Observing System Development Panel (OOSDP), convened in 1990 under the Committee on Climate Change and the Ocean (CCCO) of the Scientific Committee on Oceanic Research-Intergovernmental Oceanographic Commission (SCOR-IOC) and the International Council for Science-World Meteorological Organization (ICSUWMO) Joint Scientific Council (JSC). Building upon the successful internationally coordinated World Climate Research Programme (WCRP)'s World Ocean Circulation Experiment (WOCE), and also motivated by the Tropical Oceans Global Atmosphere (TOGA) Experiment, OOSDP was established and charged with the design of an ocean observing system for climate.

While WOCE and TOGA advanced understanding of the ocean and ocean-atmosphere dynamics and the accuracies needed in the observing system, they also promoted mechanisms for the development of internationally coordinated globalscale ocean observations including standardized quality control procedures and open and timely data sharing protocols (Siedler et al., 2001). Building on this legacy, OOSDP met for 5 years and produced a series of in-depth background reports addressing the challenges and capabilities of different elements of the ocean climate system and of the role of models in a global ocean observing effort. The work of the OOSDP culminated in a realistic but aspirational plan for ocean observations, which was assessed on the basis of feasibility versus impact, a central theme of the Framework for Ocean Observing today. The OOSDP, as the name indicates, provided the required systems development plans and gave the foundation and terms of reference of a continuing ocean observations panel.

The OOPC met for the first time in 1996, as a panel of the Global Climate Observing System (GCOS), the Global Ocean Observing System (GOOS) and WCRP. OOPC took on the mantle from OOSDP to coordinate the respective capabilities of various observing approaches (National Research Council, 1997). Given the history of its development, the focus of OOPC within GOOS was the open ocean; other panels and groups were given charge of the enclosed and shelf seas and near-shore coastal seas. The initial tasks undertaken by OOPC were a number of reviews including: the global sea level observing system given the capability of satellite altimetry, and a review of the Ship-of-Opportunity Programme (SOOP) eXpendable BathyThermograph (XBT) program given plans 
for the International Argo program. These reviews were thus prompted by the advent of new technologies and observing capability. The panel was also involved in forming the Global Ocean Data Assimilation Experiment (GODAE; succeeded by GODAE OceanView), which placed new demands on the ocean observing system.

The panel's early work culminated in the OceanObs'99 conference, which cemented the foundations of what we know now as the sustained ocean observing system for climate. From OceanObs'99 there emerged a consensus within the ocean observing communities to undertake an internationally coordinated sustained global ocean observing effort for ocean physical and carbon variables with respect to climate applications, the details of which were subsequently agreed and presented in the first GCOS Implementation Plan.

During the 2000s OOPC, with other partners, supported the establishment of a number of sustained observing networks building on the OceanObs'99 recommendations. These included the establishment of the OceanSITES moored time-series initiative in 1999, and development of the International Argo array of profiling floats in 2000. OOPC's involvement was critical to brokering data agreements and incorporating these new networks into existing programs such as SOOP and the global XBT network, and connecting to the expanding satellite missions (e.g., Sea Surface Temperature and Ocean Altimetry). In addition, OOPC co-sponsored a workshop on the Indian Ocean held in Perth, Australia, that led ultimately to the creation of a regional alliance to support GOOS in the Indian Ocean (IOGOOS). In 2001, OOPC conducted a review of the Tropical Moored Buoy Array. During this period OOPC established close and strong collaborations with WCRP including their Climate and Ocean: Variability, Predictability and Change (CLIVAR) project and other panels, ensuring both the development of a sustained ocean observing system and providing input to regional and basin process-studies. Building on the OOPC input to the establishment of GODAE, in 2002 OOPC's indirect sponsorship was vital to bringing climatechange consideration into the plan for the development of what is now the Group for High Resolution Sea Surface Temperature (GHRSST) project.

The consolidation of the OOPC activities and oversight of the ocean observing networks and sensor development culminated in the OceanObs'09 [OOPC co-led with CLIVAR and the Integrated Marine Biosphere Research (IMBeR)] conference. OceanObs' 09 recognized the utility of ocean observations beyond climate and the need to expand beyond physical variables to include biogeochemical and ecosystem variables within the ocean observing system. To this end there was strong engagement with the various ocean communities involved in ocean observations and end users. Leading up to OceanObs'09, OOPC in collaboration with the International Ocean Carbon Coordination Project (IOCCP) and CLIVAR developed a strategy for a sustained global repeat hydrography program as a contribution to the OceanObs09 Conference (Hood et al., 2010). Arising from this strategy, in 2009 the Global Ocean Shipbased Hydrographic Program (GO-SHIP) was established as a component of GOOS. A further outcome of the conference was the development of the Framework for Ocean Observing (FOO) (Lindstrom et al., 2012; Tanhua et al., 2019). The FOO provides guidelines for evolving the observing system in the service of a broad range of applications and users. To support expansion of the ocean observing system, GOOS expanded to include three disciplinary panels; OOPC became the physics and climate panel, IOCCP provides oversight of ocean biogeochemistry, and a new biology and ecosystems Panel (BioEco) was formed. OOPC retains, importantly, the dual roles as the ocean panel of GCOS and physics panel of GOOS. Delivery to GCOS requires OOPC to work across all components of GOOS.

OOPC has the demanding role of coordinating ocean input to GCOS and interacting with its sibling Terrestrial (TOPC) and Atmosphere (AOPC) GCOS panels, while also working with the other panels of GOOS. OOPC is the steward of the ocean Essential Climate Variables (ECV) of GCOS and the physical Essential Ocean Variables (EOVs) of GOOS, and hence must consider the requirements for observations across multiple time and space scales to meet users requirements from marine weather to climate, including both real-time and delayed mode data, while being mindful of complementing biogeochemistry and ecosystem observing at all scales. Since the OceanObs'09 Conference, GOOS has developed and articulated the need for ocean observation around application areas which cut across the disciplinary panels: climate, operational services, and ocean health. OOPC leads on delivery to Climate and Operational Services, and supports Ocean Health through articulating requirements for underpinning physical information. OOPC is also a panel of the WCRP, and provides scientific guidance and evaluation to observing networks through the Joint WMO IOC Technical Commission on Oceanography and Marine Meteorology (JCOMM) Observation Coordination Group.

These many responsibilities to GCOS, GOOS, WCRP, and JCOMM, spanning a broad spectrum of scales and including multiple disciplines, are demanding roles. Fundamental to delivering on these responsibilities, OOPC's, in conjunction with other programs, is undertaking regular assessments of elements of the observing system in order to provide objective guidance on the continued evolution of the system that will meet current and future user requirements.

We argue that the role of OOPC in the assessment and evolution of the observing system is becoming increasingly important given the expansion of ocean observing technologies, increased user dependency for sustained and timely ocean observations and expanding user groups. Given this, questions OOPC needs to consider are:

- How do we evolve the observing system to meet a broader range of applications, ranging from extreme events (e.g., cyclones, storms, marine heat waves, and coastal inundation forecasting) to climate monitoring and supporting ecosystem services?

- How do we maintain the interest and momentum for sustaining observations, when much of the funding is on short term cycles? 
- What actions do we need to take to keep exercising the system through reviews; engaging users, innovation, broadening participation?

- How do we continually evaluate and innovate the observing system to ensure it performs as an integrated system?

\section{DEFINING REQUIREMENTS FOR SUSTAINED OBSERVATIONS - THE ESSENTIAL OCEAN VARIABLES}

The challenge of measuring the ocean to meet the range of application needs discussed in section Societal Requirements for Ocean Observations may seem insurmountable. The Essential Ocean Variables are a tool to describe and communicate the "essential" requirements for sustained ocean observations and enable for evolution of the observing system with time. Essential Ocean Variables were inspired by the success of the Essential Climate Variables concept for articulating the critical variables that must be observed to meet user requirements (Bojinski et al., 2014).

\section{The Framework}

The Framework for Ocean Observing (Lindstrom et al., 2012) identifies lessons learned from the successes of previous and existing ocean observing efforts and provides an internationallyaccepted common language and guidance for expanded collaboration in sustained ocean observations. It is focused on:

- Delivering a system based on common requirements, coordinated ocean observing elements, and common data and information streams;

- Essential Ocean Variables (EOVs), a common focus for requirements defined based on feasibility and impact on societal and scientific drivers; and evaluation of readiness levels of sensors, platforms and data management procedures.

EOVs are identified by the GOOS Expert Panels, based on the following criteria:

Relevance: The variable is effective in addressing the overall GOOS Themes - Climate, Operational Ocean Services, and Ocean Health.

Feasibility: Observing or deriving the variable on a global scale is technically feasible using proven, scientifically understood methods.

Cost effectiveness: Generating and archiving data of the variable is affordable, mainly relying on coordinated observing systems using proven technology, taking advantage where possible of historical datasets.

When EOVs are identified, a series of recommendations are created and disseminated by the Expert Panels, including what measurements are to be made, various observing options, and data management practices. The adoption of EOVs is not intended to replace existing ocean observing networks and international coordination groups, but to provide a mechanism to bring them together to develop a holistic ocean observing system and strengthen the ocean observing communities ability to grow and best meet current and future user requirements.

\section{Key Ocean Phenomenon}

To help with the identification of scales (spatial and temporal, global, regional) and parameter spaces for a certain observing objective, OOPC has determined key or overarching ocean physical phenomena that the observing system should be able to resolve. In identifying these phenomena OOPC, considered the GOOS definition of a phenomenon as an observed process, event, or property, with characteristic spatial and timescales, measured or derived from one or a combination of EOVs, and needed to answer at least one of the scientific questions asked in order to address relevant societal need.

The list of phenomena, needed to be captured by EOVs, defined by OOPC (OOPC-19 Report) are:

- Heat storage;

- Salt storage;

- Water mass (i.e., Water properties and characteristics);

- Ocean Circulation;

- Sea level;

- Fronts and eddies;

- Stratification;

- Mixed layer;

- Sea ice;

- Air-sea fluxes;

- Upwelling;

- Coastal processes (encompassing a wide range of dynamics including, but not limited to, shelf-open ocean exchange of momentum, heat and salt);

- Tides;

- Riverine input;

- Surface waves;

- Near inertial oscillations;

- Extreme events (i.e., marine heatwaves, tsunamis, cyclones, storms).

Measurements of these key phenomena occupy a large spatial and temporal domain to meet the requirement of users (Figure 1). The phenomena span a spatial scale of 100's of meters to 1000's of kilometers and timescales of hours to centuries. These phenomena have different spatial and temporal measurement requirements from large basin-scale at annual resolution to coastal and weekly resolution. A diverse range of observing platforms are required to deliver this information including satellites, research and volunteer vessels, moorings, and surface and subsurface floats, and gliders. In addition, it is anticipated that as technologies (platform and sensors) advance, improved ocean observing techniques will be employed and these coupled with advances in telecommunications, will fill current gaps in the observing system and lead to improved impact of the observing system relative to investment (Sloyan et al., 2017). 


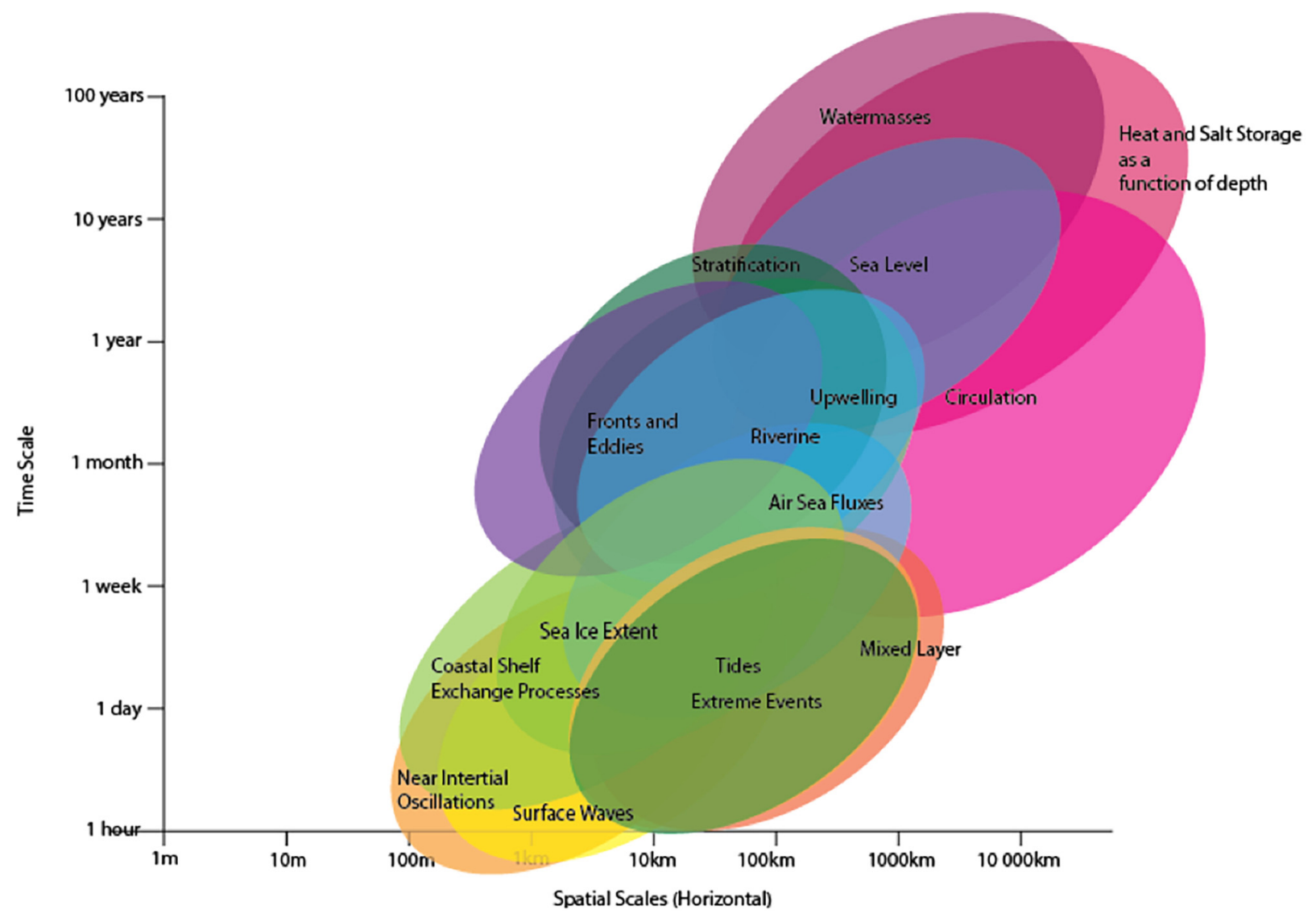

FIGURE 1 | Stommel diagram of key ocean physics phenomena that need to be derived or observed form ocean observations

\section{Essential Ocean Variables (EOVs)}

The set of key physical phenomena and processes are determined/estimated from observable ocean variables. OOPC, in conjunction with the GOOS Biogeochemistry and Biology and Ecosystem panels, motivated by the GCOS work on Essential Climate Variables (ECVs) and the strategic plan for integrated ocean observing "Framework for Ocean Observing" (FOO), have developed lists of Essential Ocean Variables (Table 1). The EOVs are judged to be the priority variables required to determine these key physical phenomena and meet most of the needs of the diverse user community. The EOVs also reflect the technical readiness to collect the observation. The selection of EOVs is based on key variables that are found to be required to describe the ocean state. They are also relevant in the context of UN Sustainable Development Goals, notably 13. Climate Action, 14. Life Below Water and 15. Life on Land. In general there are a number of observational platforms or methods used to measure an EOV. These platforms or methods may vary in their readiness level from concept to mature.

GOOS provides detailed information for each EOV including the spatial and temporal sampling requirements, identification of the key ocean processes and phenomena that require measurements of the variable, and characteristics of the observing platforms or programs that measure the variable (see www.goosocean.org for more information). The detailed EOV specification sheets demonstrate the interdependencies amongst EOVs and unique characteristics of observing platforms and programs to deliver the observations of the key ocean phenomena or process required by the diverse users of the ocean observing system. The selection of EOVs is based on their need to support improved scientific understanding and also societal needs; at the same time the mature status reflects technical readiness and feasibility of the observing methods. The importance of connecting the major drivers and themes with the societal benefits informed by scientific issues and applications, is moreover ensuring consistent identification of the EOVs and their corresponding observing element. In turn, strengths and deficiencies, synergies and interdependencies can be objectively tracked and evaluated.

The OOPC panel (and likewise the other GOOS panels) shall moderate such communication by informing the observing community. In that context, the panels have created EOVs specification documents that provide guidance on input variables, their definitions, observing platforms that sample the variables, information on accuracy, and examples for utilization of the data in the ocean observing value chain.

New scientific challenges may arise, as may societal needs. Observing technology will also evolve and improve. Thus, the 
EOVs specification sheets and EOVs will change with time to reflect need and readiness. At the same time, inclusion of the metric of readiness in the selection of mature EOVs, makes it clear that development of scientific understanding requires more progress in observation technology. For example, challenges of quantifying the large-scale heat budget of the Earth have been highlighted through the international WCRP/CLIVAR research focus "CONCEP-THEAT" (von Schuckmann et al., 2015). Quantifying the heat budget requires, for example, observation of the exchange of heat between the atmosphere and ocean at the sea surface. Ocean surface heat flux is also critically important for understanding and predicting climate variations on time scales of days to decades. The need for this observation was brought to the attention of the OOPC, and recently added ocean surface heat flux as an EOV. Ocean surface heat flux is one of the most complex EOV as it comprises both radiative and turbulent components. While ocean surface heat flux is considered an ocean ECV/EOV, its radiative components are considered atmospheric ECVs, with networks that extend over both land and ocean. Likewise, for many applications, the turbulent latent and sensible heat fluxes are estimated using a bulk algorithm applied to state variables, some or which are atmospheric ECVs, while others are oceanic ECVs. Ocean surface heat flux thus requires close coordination between all GCOS panels; Ocean, Atmosphere and Terrestrial. OOPC has thus initiated an ocean surface heat flux expert panel, with members from other GCOS panels, that will work to assess and improve capability and readiness. As one of the first activities of this group, Cronin et al. (2019) developed a strategy document for making breakthrough improvements to the gridded ocean surface heat fluxes. The ambitious strategy involves optimizing satellite-based observations for boundary layer measurement of humidity and air temperature, sea surface temperature and wind stress; and expansion of the in situ flux network. OOPC will continue to be active in evaluating this strategy and its roadmap.

CONCEPT-HEAT was also involved in highlighting the importance of observing the deep ocean. As they developed the Deep Ocean Observing Strategy under GOOS, they felt that additional observables should be considered as EOVs. To follow this up, three physical quantities were put forward to the OOPC by Deep Ocean Observing Strategy (DOOS) for consideration: notably bottom pressure, ocean mixing, and flux through the seafloor. OOPC assessed the requirements for each as well as the technical readiness and feasibility for observing on a global basis. As a result DOOS was encouraged to complete the documentation to advance bottom pressure as a potential EOV; ocean mixing and seafloor fluxes were judged to not yet be ready for identification as EOVs.

The expert panels for GOOS biogeochemistry (IOCCP) and biology/ecosystem (GOOS BioEco) follow a similar strategy to OOPC in providing structural elements as EOV and phenomena and estimating the relevant time/space and parameter space that is linked to a specific application. Ocean physics and its interaction with the marine ecosystem also plays a major role in understanding and predicting marine biology and biogeochemistry and in probably almost all of the ocean observing design for marine biology and biogeochemistry the physical processes (transport, thermodynamics) have to be considered as well. In other words, an apparently monodisciplinary experiment in marine biology or biogeochemistry is typical a multidisciplinary one involving ocean physics (and the associated sampling). Hence as we move toward an increasingly multidisciplinary observing system new challenges in a fully integrated system will need to be identified and eventually solved.

The EOV (and ECV) process very much focuses on observational quantities, meaning the sensor data and its combination with other variables. However, for the observing system and in particular for providing guidance on the individual observing networks it is mandatory to introduce a mechanism to trace each data point from the sensor mounted on an observing platform to a certain product that has been generated by the downstream services (e.g., a sea surface temperature map). Such an start-to-end evaluation is required if the complete value of the observations or observing system is required. This "value" assessment is further complicated by the interdependencies that exist in the observing system (e.g., GO-SHIP provides the highest quality observations of a suite of EOVs used by autonomous platforms for calibration). Thus assessment and attribution of value of the observing system is not a simple task.

As a common language for multi-platform global observing for the diverse user community, EOVs are fundamental to the implementation of FOO. In response to the advances in research and observing technology, OOPC will continually update specification sheets for each EOV and consider the addition of new EOVs. Moreover, increasing participation of private sectors in the ocean observing systems suggests the need to set target uncertainties for each EOV (Weller et al., 2019). The challenge that OOPC faces in keeping the EOV specifications relevant is formidable. EOV sampling requirements must acknowledge applications that span real-time weather and climate and maritime operations, fundamental ocean dynamical understanding to global climate, as well as requirements in support of ocean health applications. These are informed through strong liaison between GOOS, GCOS and JCOMM, and by the scientific and technical expertise and experience of the membership of the GOOS panels and steering committee.

\section{DATA INTEGRATION, DERIVED PRODUCTIONS AND INFORMATION DELIVERY}

Effective data management demands group collaboration across activities that include observation collection, metadata reporting and data assembly using community accepted standards, quality assurance and control (QA/QC), data publication that enables interoperable discovery and free, open access (both interactively and via machine to machine through standard protocols), and archiving that guarantees long-term preservation. Some sustained ocean observing networks are quite successful in accomplishing these data management functions, while others that are less centrally coordinated or are supported largely by research projects with short-term funding are challenged to 
TABLE 1 | GOOS essential ocean variables.

\begin{tabular}{|c|c|c|}
\hline Physics & Biogeochemistry & Biology and ecosystems \\
\hline Sea state & Oxygen & Phytoplankton biomass and diversity \\
\hline Ocean surface stress & Nutrients & Zooplankton biomass and diversity \\
\hline Sea ice & Inorganic carbon & Fish abundance and distribution \\
\hline Sea surface height & Transient tracers & Marine turtles, birds, mammals abundance and distribution \\
\hline Sea surface temperature & $\begin{array}{l}\text { Suspended } \\
\text { particles }\end{array}$ & Live coral \\
\hline Subsurface temperature & Nitrous oxide & Seagrass cover \\
\hline Surface currents & $\begin{array}{l}\text { Stable carbon } \\
\text { isotopes }\end{array}$ & Macroalgal canopy \\
\hline Subsurface currents & $\begin{array}{l}\text { Dissolved organic } \\
\text { carbon }\end{array}$ & Mangrove cover \\
\hline Sea surface salinity & Ocean color & Microbe biomass and diversity (*emerging) \\
\hline Subsurface salinity & & Benthic Invertebrate Biomass and Diversity. (*emerging). \\
\hline Ocean surface heat flux & & \\
\hline
\end{tabular}

OOPC is responsible for physics variables.

operate consistently. They may employ varying data policies and submission requirements, and may lack the resources to engage experienced staff to review and QA/QC data flowing from disparate providers or to offer cyberinfrastructure services that achieve the level of service to match more mature networks. Recent publication discuss many aspects of data management (e.g., Moltmann et al., 2019; Pinardi et al., 2019; Snowden et al., 2019); here we address the need for EOVs data collections.

Where EOV data are handled by a multitude of disparate data management infrastructures this imposes problems for the global observing system. These include, but are not limited to, delayed and duplicate data receipts, versioning issues, missing data and metadata, and undocumented data processing procedures, and data recovery. If data quality and supporting metadata are to carry over from observers to products then modern data management infrastructures are essential at every step along the data flow pipeline, from data recovery, collection through assembly and to preservation. The more automated and fault tolerant these steps are, the more they embrace community standard practices and the more efficiently and swiftly will systems advance toward the levels of reliability and interoperability that user communities seek. The Committee on Earth Observations Satellites (COES) and the International Quality controlled Ocean Database (IQuOD) are examples of groups that are focused on providing the community with high quality data that has a consistent and unified quality control standard applied. OOPC needs to support and promote these activities and products, respectively.

Interoperability serves both routine data flow within and amongst the networks, and user discovery and access. Community standards for metadata, data formats, communication protocols, and data server software infrastructure are the foundation for interoperability. These are not new considerations for the ocean data management community. The technical aspects have been demonstrated and successfully deployed in many regions and specific parts of the global networks. Expanding on these successes is important, and is being guided by various ocean observing programs led by individual national efforts, regional and international groupings, as well as by coordinating organizations independently and jointly in the WMO and IOC. The time is right to improve interoperability across the observing system networks and enable sustainable process that can create integrated datasets for the EOVs.

A data collection for EOVs must ensure the following:

- Data are quality assured and controlled according to agreed international standards;

- Feedback is given to the data sources as needed;

- Duplicates are identified and resolved;

- Metadata are complete and meet agreed best practices and existing standards;

- Data and metadata are discoverable and accessible through interoperable services;

- Data requests and searches from users can be reproduced;

- Data and metadata are electronically published with protocols for citation and acknowledgment;

- The complete provenance and lifecycle of data processing is traceable for each ECV/EOV dataset.

In addition to cataloging and preserving data and enabling effective delivery to users, these practices help ensure that observing programs/platforms and organizations get credit for data they make available and that users and reviewers can repeat precise requests for data referenced in scientific publications for the purposes of reproducing, verifying or expanding upon and enhancing prior work.

By providing interoperable access, and adhering to standards and conventions, this framework makes data synthesis efforts more efficient than with the less-integrated data management systems that exist in many quarters. It is such data synthesis efforts, founded on quality assured observational products, that deliver integrated assessments of regional and global ocean climate change and variability. 
We note that the periodical re-calculation of integrated gridded climatologies or model-data ocean and coupled atmosphere-ocean reanalysis products, such as is performed to inform State of the Ocean reports (e.g., von Schuckmann et al., 2018) and the IPCC process, are greatly facilitated by the existence of a stable, robust and interoperable data management and delivery system. Every effort should be made to sustain and enhance this data stream following the guiding principles, and for the reasons, noted above.

\section{PERIODIC REVIEWS OF THE OBSERVING SYSTEM}

From OOPC's perspective, a virtue of the EOV concept is that it helps guide global coordination of the ocean observing system through articulating requirements in a platform/sensor agnostic way. The EOV specification sheets emphasize requirements for accuracy, sampling resolution and frequency, and the timeliness of data delivery, without immediately calling out how these requirements might be met in terms of existing sensor types or scope of deployments. The actual deployments will always be the domain of the various expert observing networks (both in situ and satellite) and the national and international agencies that fund them. OOPC should advocate for national investment in the observing platforms.

Increasing use of the ocean observing system has driven OOPC to lead, support or provide substantive input to a number of systems-based-reviews of the observing system, some of which are developing into finite-lifetime development projects:

- 2011: The Deep Ocean Observing Strategy (DOOS) (Levin et al., 2019);

- 2014: The Tropical Pacific Observing System (TPOS) 2020 project (Smith et al., 2019);

- 2019: Ocean heat and freshwater review (Palmer et al., 2019);

- 2019: Air-Sea fluxes with focus on heat and momentum (Cronin et al., 2019);

- 2019: Boundary Currents (Todd et al., 2019);

- 2019: AtlantOS and the Atlantic blueprint (deYoung et al., 2019).

OOPC has also advised on two reviews led by the CLIVAR expert panels:

- 2019: Indian Ocean Observing System Review;

- 2019: Tropical Atlantic Observing System Review.

These system- or regional-based reviews are driven from the need to observe various targeted phenomenon, science questions and expanded user requirements. In this context an ongoing challenge for the stakeholders of the ocean observing system is designing, implementing and sustaining critical observations required by the diverse users groups. In addition, it is a significant challenge for OOPC to draw on these regional and thematic review and development activities to facilitate advancing the global observing effort in a consistent way.
To this end it would be valuable to turn to the community of global and regional modeling systems that formally meld data from the full suite of observing platforms with models using advanced data assimilation to derive ocean state estimates in support of reanalysis applications and weather-scale and subseasonal to seasonal and decadal prediction. For these groups, observations are vital to constraining the ocean state, and are the fundamental metric against which forecast skill is evaluated. Many such groups are also advanced service providers, and are important links in the value chain that translates observations into information products and OOPC needs to liaise with major institutions providing operational climate and environmental services. Where the observing network falls short in informing the analyses that underpin derived products generated by the service providers, it is important that this is communicated back to OOPC and GOOS to establish priorities for observing system enhancement.

The ocean modeling and analysis research communities and many operational centers have formulated and prototyped quantitative tools for rigorous assessment of the impact that individual observations or networks have on analysis and forecast skill. Though their use is not routine, such tools have the potential to systematically identify observational gaps and to evaluate new or revised deployment strategies or platforms to more effectively meet user requirements. More widespread analyses of observation gaps and EOV requirements by modeling groups would be a welcome addition to the OOPC-sponsored or coordinated network reviews. Modeling groups that emphasize product delivery to stakeholder communities are also well placed to advise on changing EOV requirements to inform new data uses, including beyond physics variables to multidisciplinary EOV.

Additionally, assimilation of similar data from multiple platforms, each with its estimate of accuracy, can help identify biases or inconsistencies in the data. Where models and data frequently disagree also identifies needs for improved model dynamics and parameterizations. By delivering formal expected errors of the merged analyses, these systems highlight where the observing network is sparse and in need of expansion. When executed with hypothetical data sets, these systems can offer rigorous assessments of observing system design and significantly inform and prioritize the need for new observations.

There remain many unanswered questions on the fundamental nature and drivers of the oceans on climate processes and feedbacks amongst the components of the Earth's climate system; atmosphere, terrestrial, cryosphere, oceans, and biosphere. Improved dynamical understanding of the ocean, land, ice and atmosphere, and the ocean-atmosphere-ice-land coupling and teleconnections will lead to more reliable and skillful multi-year to decadal climate forecasts. Key to improved knowledge are intensive process studies that integrate both observation and models and target specific key knowledge gaps. Leveraging existing components of the sustained observing system with short-period intensive process studies may prove an effective mechanism to achieve significant advancement of ocean and earth sciences. 
As we look to the next decade, OOPC must ensure that ocean observations are sustained and evolve to best meet the needs of our sponsoring programs GCOS-GOOS-WCRP and other user requirements. The assessment and recommendation of the evolution of the observing system should balance user requirements such as, providing improved knowledge of underpinning ocean dynamics, ocean state monitoring for assessment, and adaptation and mitigation, marine services operational weather and marine forecasting that encompass regional, basin and global scales and seasonal to decadal predictions systems. In addition, with the establishment of the biogeochemical and biological/ecosystem panels, GOOS has recognized that ocean observing in the service of existing and emerging users ultimately requires a multi-disciplinary approach. As such, the physics component will increasingly be integrated with biogeochemical and ecosystem observing sensors and platforms. This will require close collaboration amongst all GOOS panels.

We suggest that expanding model-based assessments of the accuracy and effective resolution of observing networks would be a valuable step in refining the guidance in the EOV specifications with respect to sampling resolution and frequency. There is an increasing need to assess the current and future observing system capabilities in light of the climate variability and potential climate change response that we can anticipate from both climate modeling systems and our existing knowledge and oceanographic theory. For example, closure of global energy and sea level budgets will increasingly demand improved sampling below $2000 \mathrm{~m}$ as the global warming signal propagates downward (Gleckler et al., 2016; von Schuckmann et al., 2016).

\section{AN INTEGRATED, SUSTAINED AND PRIORITIZED OCEAN OBSERVING SYSTEM FOR THE FUTURE}

Despite century-long efforts, observations are still limited for many parts of the global ocean. The ocean observing system must continue to evolve to maximize support for climate monitoring, process understanding, development of improved numerical models, and prediction of weather and climate on a range of timescales. Meeting societal needs will require more reliable ocean data for prediction of extreme events and their intensity and frequency distribution, monitoring of Earth's climate cycles (heat, water, and carbon) to inform discussion and development of mitigation and adaptation policy, marine forecasting, and weather to climate predictions and projections.

The OceanObs'09 Framework for Ocean Observing (Lindstrom et al., 2012) sets a foundation for how the GOOS a multiplatform, multidisciplinary and multifunctional ocean observing system - might evolve. However, it is recognized that the implementation of the observing system relies heavily on champions at the national level to bring the plan to reality. OOPC enables connections between the various observing systems/platforms and national implementers of the observing system to leverage the necessary funding from national agencies. OOPC's advocates for and endorsement of the ocean observing systems, through scientifically-informed assessments of stakeholder needs and observing system capabilities. Thus, OOPC's role is to provide objective advice, representing a wider community view of the observing system as a whole and acts as a broker between stakeholders, national agencies and intergovernmental constructs.

It is expected that through OceanObs'19, many communitydriven ideas will be voiced for improving the GOOS. Some of these recommendations may be readily implemented by new and current operators, while others may require trade-offs and/or international support and coordination. Transitioning to new observing system designs, for example, can be disruptive to long climate records that seek to minimize artifacts associated with changes in the measurement techniques and sampling characteristics that may mask the underlying climatic signals. Indeed, the next decade will present a number of opportunities that may enable genuine growth of the ocean observing system and the potential to provide a more secure funding mechanisms in future. The recent declaration of the United Nations Decade of Ocean Science for Sustainable Development (2021-2030) aims to provide ocean science, data and information to inform policy for a well-functioning ocean in support of all sustainable development goals of the Agenda 2030. This will generate scientific knowledge, underpinning infrastructures and partnerships and will require a cohesive GOOS across the coastal/shelf seas to the open ocean. OOPCs international coordination will be integral to building an integrated, sustained and prioritized ocean observing system and fostering cooperation with the GOOS biogeochemistry and biological/ecosystem expert panels, the JCOMM Observations Coordination Group, and GCOS.

\section{SUMMARY AND RECOMMENDATIONS}

OOPC, over the last 3 decades, has provided international guidance and a collaborative framework for the global ocean observing efforts that support fundamental research related to understanding and monitoring ocean physics and climate. More recently we have witnessed an acceleration in the technical capacity to deliver high quality observations in near-real time. This capacity for real-time data delivery has resulted in increasing demands for ocean observations in support of operational weather and maritime forecasting. Meteorological and ocean operational service providers have demonstrated how expanded ocean observations support the provision of improved forecasts and novel derived products of value to numerous user communities. OOPC needs to develop an inclusive partnership with these users to ensure support for the development and maintenance of the observing system.

Designing and operating a multidisciplinary observing system that goes beyond the physical ocean state into biogeochemistry and ecosystems will demand an even greater level of coordination and an expanded view of the phenomena that drive requirement specification. This will be accomplished by strong connections and collaborations between OOPC and the other GOOS panels, and it will fall on OOPC to provide informed consensus 
leadership on the expanding requirements for multidisciplinary ocean observing.

The heterogeneous nature of observing technology and the expanding sensors and platforms used, present great opportunities and challenges for the observing system. Coordination amongst disparate networks has the potential to offer efficiencies or enhanced complementarity of platforms. OOPC, with its responsibility to consider the observing system as a whole and its platform agnostic stewardship of the EOV/ECV requirements, is the natural forum to foster this coordinated evolution of the observing system. OOPC needs to ensure the observing system develops in a coordinated way and that data remain openly accessible in a timely manner. The synthesis and delivery of higher-level derived products based upon direct observations in support of research, operational and climate applications is a major scientific undertaking that demands significant added investment of both money and people. It is only through the coordinated synthesis of all observations for a given EOV that integrated observational datasets that meet user requirements and expand the use of the data will be achieved.

OOPC oversight and endorsement of ocean observing system reviews (e.g., TPOS2020, TAOS, IndOOS) and design studies for future systems (DOOS) is not currently undertaken in a consistent way. To ensure that these interconnected components of a global observing system are consistent, OOPC needs to provide a set of common guidelines to frame these review or design studies. Inevitably, there remain knowledge gaps in our understanding of how the ocean influences Earth's weather and climate across the full spectrum from daily to interannual and multidecadal time scales. Intensive short-term hypothesis-led observing studies targeted at specific processes are vital contributors to advancing our understanding of the oceans' influence on climate processes. Support for intensive ocean process studies will stand on their own intrinsic scientific merits, but may identify shortcomings in the global observing system, its design, its operation, or its fitness to deliver multidisciplinary objectives, OOPC should support the need for specific process studies wherever these emerge.

Key recommendations for OOPC to ensure that the ocean observing system delivers a globally integrated and consistent fit-for-purpose ocean observing system are:

1. OOPC should enhance links between observing networks and operational services that use data to generate higher level information products. Because of their dependency on these data, operational and modeling communities have a significant interest in supporting sustained ocean observing, and in offering guidance to ensure the system delivers data that meet evolving user needs.

2. OOPC should formulate a set of common principles for observing system evaluation and design. These will draw on the FOO and provide a consistent set of guidelines for the conduct of reviews, their terms of reference, and the reporting of their outcomes. It would be appropriate for OOPC to assume an oversight role in monitoring adherence to these principles to ensure that the guidelines are implemented consistently.

3. Under OOPC leadership, regular reviews of the EOV/ECV requirements should be undertaken to ensure they meet existing and emerging user needs. OOPC, with OCG, will work with observing networks to build unified data management practices to build consistent and findable data systems. OOPC must be a strong advocate that enables national implementers of the observing system to secure funding from national resources.

4. OOPC will support the coordination of EOV data collections, and production of synthesis and higher level products that users value. OOPC will publicize these products to increase data update and demonstrate to funders the value of these synthesis projects and need for ongoing resourcing of such efforts.

5. OOPC, in coordination with research partners (e.g., WRCP), will advocate for intensive process studies to address knowledge gaps.

\section{CONCLUSION}

The ever increasing complexity of the Ocean Observing System both in terms of the observation techniques and users requirement calls for a strong and robust management and evaluation process. OOPC provides an internationally recognized and supported mechanism for coordinating the review and evolution of existing observing systems that is essential to meeting the wide range of current and future user requirements.

Providing leadership on the continual assessment of the observing and data system, identifying gaps, risk and user needs is a central task of OOPC. We will continue these efforts reviewing existing observing systems and recommending unified data management and formats, all the while keeping in mind how their integration and expansion into multifunctional, multidisciplinary systems will meet an expanding range of user requirements. These review processes and the proposal of new observations require input and collaboration amongst the observing platforms/programs (satellite and in situ), research and user communities and insights from climate models and other modeling systems. Where reviews of regions or themes suggest continuation or expansion of observations, OOPC will be a strong advocate for continued support of the ocean observing system.

\section{AUTHOR CONTRIBUTIONS}

$\mathrm{KH}$, JW, and $\mathrm{BS}$ led the conception and writing of the manuscript. MPC, MFC, JJ, JK, MK, TL, EO, MP, BR, SS, KvS, RW, and WY contributed to the text.

\section{FUNDING}

BS received support from the Centre for Southern Hemisphere Oceans Research, a collaboration between the CSIRO and 
the Qingdao National Laboratory for Marine Science and Technology and the Australian Government Department of the Environment and CSIRO through the Australian Climate Change Science Programme and by the National Environmental Science Program. JK was supported by the European Union's Horizon 2020 Research and Innovation Programme under the grant agreement no. 633211 (AtlantOS). MP was supported by the Met Office Hadley Centre Climate Programme funded by the BEIS and Defra. SS was supported by the Ecole Normale Supérieure, CNRS, and Ifremer funded by the European Union's Horizon 2020 Research and Innovation Programme

\section{REFERENCES}

Bojinski, S., Verstraete, M., Peterson, T. C., Richter, C., Simmons, A., and Zemp, M. (2014). The concept of essential climate variables in support of climate research, applications, and policy. Bull. Amer. Meteor. Soc. 95, 1431-1443. doi: 10.1175/BAMS-D-13-00047.1

Caesar, L., Rahmstorf, S., Robinson, A., Feulner, G., and Saba, V. (2018). Observed fingerprint of weakening atlantic ocean overturning circulation. Nature 556, 191-196. doi: 10.1038/s41586-018-0006-5

Cronin, M. F., Gentemann, C. L., Edson, J., Ueki, I., Bourassa, M., Brown, S., et al. (2019). Air-sea fluxes with a focus on heat and momentum. Front. Mar. Sci. 6:430. doi: 10.3389/fmars.2019.00430

deYoung, B., Visbeck, M., de Araujo Filho, M. C., Baringer, M. O., Black, C.-A., Buch, E., et al. (2019). An integrated all-Atlantic Ocean observing system in 2030. Front. Mar. Sci. 6:428. doi: 10.3389/fmars.2019.00428

Doblas-Reyes, F. J., GarcíaSerrano, J., Lienert, F., Biescas, A. P., and Rodrigues, L. (2013). Seasonalclimate predictability and forecasting: status and prospects. WIREs Clim. Change 4, 4245-4268. doi: 10.1002/wcc.217

Duchez, A., Frajka-Williams, E., Josey, S. A., Evans, D. G., Grist, J. P., Marsh, R., et al. (2016). Drivers of exceptionally cold north atlantic ocean temperatures and their link to the 2015 European heat wave. Environ. Res. Lett. 11:074004. doi: 10.1088/1748-9326/11/7/074004

Frajka-Williams, E., Beaulieu, C., and Duchez, A. (2017). Emerging negative atlantic multidecadal oscillation index in spite of warm subtropics. Sci. Rep. 7, 11224. doi: 10.1038/s41598-017-11046-x

Gleckler, P. J., Durack, P. J., Stouffer, R. J., Johnson, G. C., and Forest, C. E. (2016). Industrial-era global ocean heat uptake doubles in recent decades. Nat. Clim. Chang. 6, 394-398. doi: 10.1038/nclimate2915

Gould, J., Sloyan, B. M., and Visbeck, M. (2013). "In-situ ocean observations: a brief history present status and future directions," in Ocean Circulation and Climate: A 21st Century Perspective, 2nd Edn eds G. Siedler, S. Griffies, J. Gould, and J. Church (Sydney: Academic Press), 59-79.

Hobday, A. J., Oliver, E. C. J., Sen Gupta, A., Benthuysen, J. A., Burrows, M. T., Donat, M. G., et al. (2018). Categorizing and naming marine heatwaves. Oceanography 31, 162-173. doi: 10.5670/oceanog.2018.205

Hood, E. M., Fukasawa, M., Gruber, N., Johnson, G. C., Körtzinger, A., Sabine, C., et al. (2010). "Ship-based repeat hydrography: a strategy for a sustained global survey," in Proceedings of OceanObs'09: Sustained Ocean Observations and Information for Society, Vol. 2 eds J. Hall, D. E. Harrison, and D. Stammer (Venice: ESA publication), 21-25.

Hughes, T. P., Kerry, J. T., Baird, A. H., Connolly, S. R., Dietzel, A., and Eakin, C. M. (2018). Global warming transforms coral reef assemblages. Nature 556:492. doi: 10.1038/s41586-018-0041-2

IPCC (2014). Climate Change (2014). Synthesis Report. Contribution of Working Groups I, II and III to the Fifth Assessment Report of the Intergovernmental Panel on Climate Change. Cambridge: Cambridge University Press.

Johnson, G. C., Lyman, J. M., Boyer, T., Cheng, L., Domingues, C. M., Gilson, J., et al. (2018). Ocean Heat Content. State of the Climate in 2017. Silver Spring, MA: NOAA.

Jones, J. M., Gille, S. T., Goosse, H., Abram, N. J., Canziani, P. O., Charman, D. J., et al. (2016). Assessing recent trends in high-latitude southern hemisphere surface climate. Nat. Clim. Chang. 6, 917-926. doi: 10.1038/nclimate 3103 under the grant agreement no. 633211 (AtlantOS), CNES, and ANR grants.

\section{ACKNOWLEDGMENTS}

We thank the scientific experts and observing programs who contributed to the development of the EOV specification sheets. We also thank David Legler for his valued contribution to OOPC activities. Comments from the reviewers improved the manuscript.

Kirtman, B., Stockdale, T., and Burgman, R. (2013). “The Ocean's role in modeling and predicting seasonal to-interannual climate variations," in Ocean Circulation and Climate: A 21st Century Perspective, 2nd Edn eds G. Siedler, S. Griffies, J. Gould, and J. Church (Sydney: Academic Press), 625-643. doi: 10.1016/b9780-12-391851-2.00024-6

Kummu, M., de Moel, H., Salvucci, G., Viviroli, D., Ward, P. J., Varis, O., et al. (2016). Over the hills and further away from coast: global geospatial patterns of human and environment over the 20th-21st centuries. Environ. Res. Lett. 11:034010. doi: 10.1088/1748-9326/11/3/03 4010

Levin, L. A., Bett, B. J., Gates, A. R., Heimbach, P., Howe, B. M., Janssen, F., et al. (2019). Global observing needs in the deep ocean. Front. Mar. Sci. 6:241. doi: 10.3389/fmars.2019.00241

Lindstrom, E., Gunn, J., Fischer, A., McCurdy, A., and Glover, L. K. (2012). “A Framework for Ocean Observing," in Proceedings of the Task Team for an Integrated Framework for Sustained Ocean Observing, UNESCO 2012 (revised in 2017), IOC/INF-1284 rev.2, Venice

Lopez, H., Dong, S., Lee, S.-K., and Goni, G. (2016). Decadal modulations of interhemispheric global atmospheric circulations and monsoons by the South Atlantic meridional overturning circulation. J. Clim. 29, 1831-1851. doi: 10. 1175/JCLI-D-15-0491.1

Marzeion, B., and Levermann, A. (2014). Loss of cultural world heritage and currently inhabited places to sea-level rise. Environ. Res. Lett. 9:34001.

Meehl, G. A., Goddard, L., Boer, G., Burgman, R., Branstator, G., Cassou, C., et al. (2014). Decadal climate prediction an update from the trenches. Bull. Am. Meteorol. Soc. 95, 243-267. doi: 10.1175/BAMS-D-12-00241.1

Miloslavich, P., Bax, N. J., Simmons, S. E., Klein, E., Appeltans, W., AburtoOropeza, O., et al. (2018). Essential ocean variables for global sustained observations of biodiversity and ecosystem changes. Glob. Change Biol. 2018, 2416-2433. doi: 10.1111/gcb.14108

Moltmann, T., Zhang, H.-M., Turton, J. D., Nolan, G., Gouldman, C. C., Griesbauer, L., et al. (2019). GOOS regional alliances enhance global ocean observing for regional and national benefit. Front. Mar. Sci. 6:291.

National Research Council (1997). The Global Ocean Observing System: Users, Benefits, and Priorities. Washington, DC: National Academies Press.

Palmer, M. D., Durack, P., Chidichimo, M. P., Church, J., Cravatte, S. E., Hill, K. L., et al. (2019). Adequacy of the ocean observation system for quantifying regional heat and freshwater storage and change. Front. Mar. Sci. doi: 10.3389/fmars. 2019.00416

Pinardi, N., Stander, J., Legler, D., O’Brien, K., Boyer, T., Cuff, T., et al. (2019). JCOMM: role and Vision. Front. Mar. Sci.

Siedler, G., Church, J., and Gould, J. (2001). Ocean Circulation and Climate: Observing and Modelling the Global Ocean. Cambridge, MA: Academic Press.

Sloyan, B., Craw, P., King, E., Neill, C., Kloser, R., and Bodrossy, L. (2017). "Future technologies," in Oceans: Science and solutions for Australia, Clayton South, ed. B. Mapstone (Australia: CSIRO Publishing), 179-186.

Smith, D. M., Scaife, A. A., and Kirtman, B. (2012). What is the current state of scientific knowledge with regard to seasonal and decadal forecasting. Environ. Res. Lett. 7:015602. doi: 10.1088/1748-9326/7/1/015602

Smith, N., Kessler, W. S., Cravatte, S., Sprintall, J., Wijffels, S., et al. (2019). Tropical pacific observing system. Front. Mar. Sci. 6:31. doi: 10.3389/fmars.2019. 00031 
Snowden, D., Belbeoch, M., Burnett, B., Carval, T., Graybeal, J., Habermann, T., et al. (2019). Framework for ocean observing: interoperability and vision. Front. Mar. Sci.

Tanhua, T., Fischer, A., and McCurdy, A. (2019). Successes and challenges in applying the framework for ocean observing. Front. Mar. Sci.

Tedeschi, R. G., Grimm, A. M., and Cavalcanti, I. F. A. (2016). Influence of central and east ENSO on precipitation and its extreme events in south america during austral autumn and winter. Int. J. Climatol. 36, 4797-4814. doi: 10.1002/joc. 4670

Timmermann, A., An, S. I, Kug, J. S., Jin, F. F., Cai, W., Capotondi, A., et al. (2018). El Niño-southern oscillation complexity. Nature 559, 535-545.

Todd, R., Chavez, F. P., Clayton, S., Cravatte, S., Goes, M., Graco, M., et al. (2019). Global perspectives on observing ocean boundary current systems. Front. Mar. Sci.

Vecchi, G. A., and Soden, B. J. (2007). Increased tropical Atlantic wind shear in model projections of global warming. Geophyis. Res. Lett. 34:L08702. doi: 10.1029/2006GL028905

von Schuckmann, K., Palmer, M. D., Trenberth, K. E., Cazenave, A., Chambers, D., Champollion, N., et al. (2015). A Prospectus for the CLIVAR Research Focus "Consistency Between Planetary Energy Balance and Ocean Heat Storage (CONCEPT-HEAT)". WCRP Report No. 14/2015. Geneva: WCRP.

von Schuckmann, K., Palmer, M. D., Trenberth, K. E., Cazenave, A., Chambers, D., Champollion, N., et al. (2016). An imperative to monitor Earth's energy imbalance. Nat. Clim. Chang. 6, 138-144. doi: 10.1038/nclimate 2876 von Schuckmann, K. P.-Y., Le Traon, N., Smith, A., Pascual, P., Brasseur, K., Fennel, S., et al. (2018). Copernicus marine service ocean state report. J. Operat. Oceanogr. 11, s1-s142.

Webster, P. J., Holland, G. J., Curry, J. A., and Chang, H. R. (2005). Changes in tropical cyclone number, duration, and intensity in a warming environment. Science 309, 1844-1846. doi: 10.1126/science.1116448

Weller, R. A., Baker, D. J., Glackin, M. M., Roberts, S. J., Schmitt, R. W., Twigg, E. S., et al. (2019). The challenge of sustaining ocean observations. Front. Mar. Sci. 6:105. doi: 10.3389/fmars.2019.00105

Yin, J., Schlesinger, M. E., and Stouffer, R. J. (2009). Model projections of rapid sealevel rise on the northeast coast of the United States. Nat. Geosci. 2, 262-266. doi: $10.1038 /$ ngeo462

Conflict of Interest Statement: The authors declare that the research was conducted in the absence of any commercial or financial relationships that could be construed as a potential conflict of interest.

Copyright (c) 2019 Sloyan, Wilkin, Hill, Chidichimo, Cronin, Johannessen, Karstensen, Krug, Lee, Oka, Palmer, Rabe, Speich, von Schuckmann, Weller and Yu. This is an open-access article distributed under the terms of the Creative Commons Attribution License (CC BY). The use, distribution or reproduction in other forums is permitted, provided the original author(s) and the copyright owner(s) are credited and that the original publication in this journal is cited, in accordance with accepted academic practice. No use, distribution or reproduction is permitted which does not comply with these terms. 